\title{
Application and analysis of debris-flow early warning system in Wenchuan earthquake-affected area
}

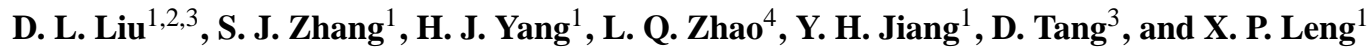 \\ ${ }^{1}$ Key Laboratory of Mountain Hazards and Earth Surface Process, Institute of Mountain Hazards and Environment, \\ Chinese Academy of Sciences, Chengdu, 610041, China \\ ${ }^{2}$ University of Chinese Academy of Sciences, Beijing, 100049, China \\ ${ }^{3}$ College of Software Engineering, Chengdu University of Information and Technology, Chengdu, 610225, China \\ ${ }^{4}$ Public Meteorological Service Center of CMA, China Meteorological Administration, Beijing, 100081, China
}

Correspondence to: S. J. Zhang (sj-zhang@imde.ac.cn)

Received: 29 July 2015 - Published in Nat. Hazards Earth Syst. Sci. Discuss.: 30 September 2015

Revised: 24 December 2015 - Accepted: 16 January 2016 - Published: 19 February 2016

\begin{abstract}
The activities of debris flow (DF) in the Wenchuan earthquake-affected area significantly increased after the earthquake on 12 May 2008. The safety of the lives and property of local people is threatened by DFs. A physicsbased early warning system (EWS) for DF forecasting was developed and applied in this earthquake area. This paper introduces an application of the system in the Wenchuan earthquake-affected area and analyzes the prediction results via a comparison to the DF events triggered by the strong rainfall events reported by the local government. The prediction accuracy and efficiency was first compared with a contribution-factor-based system currently used by the weather bureau of Sichuan province. The storm on $17 \mathrm{Au}$ gust 2012 was used as a case study for this comparison. The comparison shows that the false negative rate and false positive rate of the new system is, respectively, 19 and $21 \%$ lower than the system based on the contribution factors. Consequently, the prediction accuracy is obviously higher than the system based on the contribution factors with a higher operational efficiency. On the invitation of the weather bureau of Sichuan province, the authors upgraded their prediction system of DF by using this new system before the monsoon of Wenchuan earthquake-affected area in 2013. Two prediction cases on 9 July 2013 and 10 July 2014 were chosen to further demonstrate that the new EWS has high stability, efficiency, and prediction accuracy.
\end{abstract}

\section{Introduction}

After the Wenchuan earthquake on 12 May 2008, large areas of slopes were determined to be potentially unstable (Zhang et al., 2016). These can be readily transformed into landslides by intensive rainfall and thereby supply abundant loose solid material for debris flow (DF) formation. The increasing availability of solid material enhanced the activity of DFs, especially in the earthquake-affected area. The enhanced DFs will threaten the lives and property of local residents for a substantial period of time (Tang et al., 2009; Xie et al., 2009). The construction of DF control projects is an effective mode of DF defense. However, there are so many DF valleys in need of disaster mitigation that the construction of DF control works will cost a great deal of money and take a long time (Papa et al., 2013). Therefore, building an early warning system (EWS) to predict DFs within the Wenchuan earthquake-affected area is essential for disaster mitigation.

Disasters such as floods, landslides, collapses, and DFs can be predicted using EWSs. However, the EWSs in this study will only focus on the function of DF prediction. The EWS has become an essential feature of civil protections and is commonly recognized as a vital risk prevention tool (European Commission D. G. Environment, 2008). In recent years, there has been a tendency towards increasing the number of operational landslide and DF EWSs (Berenguer et al., 2015). For example, the EWS used for predicting DF and landslides in Japan (Osanai et al., 2010), the landslide EWS in Hong Kong (Chen and Lee, 2004), as well as some regional sys- 
tems for DF prediction in China (Wei et al., 2007) and in Italy (Aletti, 2004). All the mentioned EWSs are based on the empirical rainfall thresholds derived from the analysis of past rainfall events that induced DF. Since the pioneering work by Caine (1980), empirical rainfall thresholds for shallow landslides and DFs have been developed at local, regional, and global scales (Giannecchini et al., 2012; Borga et al., 2014; Vennari et al., 2014). However, rainfall thresholds can only be obtained from the DF valleys where certain amounts of rainfall information and related DF data are available (Papa et al., 2013; Zhang et al., 2014b). Additionally, Guzzetti et al. $(2007,2008)$ reported that a majority of empirical rainfall thresholds available in the literature were defined using nonobjective and poorly reproducible methods (Gariano et al., 2015). The above-mentioned problems in identifying empirical rainfall thresholds are mainly attributable to the lack of a physical framework of DF formation, and hence the accuracy of an EWS based on this empirical mode is relatively low (Wei et al., 2004). For example, a false positive rate of approximately $40 \%$ is reported for threshold relationships in the Alpine region (Badoux et al., 2012). A physics-based EWS that accounts for the formation mechanism of DF is a potential path to solving these issues (Zhang et al., 2014a; Papa et al., 2013).

The evolution of shallow landslides into DF is one type of formation mechanism. It is believed that this evolution is derived from a single slope (Iverson et al., 1997). This evolution process is now generally accepted as "the slope debris flow" (Li et al., 2010) or "debris flow on slope" (Zeng et al., 2004; Berti and Simoni, 2005; Kim and Lee, 2015). This type of debris flow formation has been well studied, and its corresponding prediction models have been established based on the common view that pore water pressure is the key factor triggering this type of DF formation (Cui, 1991; Iverson et al., 1997). However, these prediction models do not allow conclusions regarding whether there will be DF formation at a catchment level, as they tend to focus on a single slope. The debris flow formation at the catchment scale is defined as the gully-type debris flow (Ni, 2015). For example, debris flows that occur in the Jiangjia gully are a typical gully-type debris flow, and landslides are the dominate mechanism of supplying the material for debris flow in this gully (Kang, 1987). Coe et al. (2008) identified the Chalk Cliffs in the USA as producing runoff-induced debris flow, as they found that there was no landslide source when debris flow occurred. Kean et al. (2013) agreed with this identification result during field observation of Chalk Cliffs. These observation results lead us to conclude that rainfall-induced landslides are another kind of supplementary mode to provide material for debris flow formation at a watershed level, in contrast to the entrainment of river bed sediment material for debris flow formation. The volume of expected point source landslides is key in understanding the timing and volume forecasting for DFs (Borga et al., 2014). Papa et al. (2013) argued that the total number of rainfall-induced landslides is the key factor for
DF formation in a watershed, and he used a variable to relate failure percentages of landslides to intensity-duration (I-D) curves. Using the curve and forecasted rainfall data, DF in a watershed can then be predicted. This pioneering work can derive an I-D curve from a certain number of physical numerical simulations regardless of whether adequate observation data are available in a watershed. As a consequence, this method overcomes the drawback of empirical mode that depends on a large amount of rainfall and DF data. However, the Papa model is only a quasi-physically based method, because it attempted to predict DF in a watershed without accounting for the effect of rainfall-induced runoff.

In fact, rainfall-induced landslides and rainfall (or rainfallinduced runoff) are the two necessary factors for DF formation, and the interactions between them can induce DF formation at a watershed scale (Cui et al., 2013). Hence one can see that the descriptions of DF formation at a watershed scale can be divided into two coupling stages. The first stage involves the interaction between rainfall and slopes leading to soil-mass failure, and the second stage includes rainfallinduced runoff and solid material from landslides leading to DF formation (Zhang et al., 2014b).

According to descriptions of the two main coupling processes, the authors developed a prediction model based on water-soil coupling mechanism. In this model, the total volume of rainfall-induced landslide and runoff is simulated at each time step in the first stage, and based on which, the density of the soil-water mixture is calculated. In the second simulating stage, using the density of the soil-water mixture as the key parameter, the formation probability of DF at a watershed scale is identified. This model has been applied at different spatial scales (Jiangjia valley in Yunnan province, China; Sichuan province, China) to verify its precision and applicability, and the forecasting results are excellent with low false-negative and false-positive rates (Zhang et al., 2014a, b).

Based on this forecasting model, the main objective of this work is to develop an EWS for DF forecasting that accounts for the formation mechanism of DF at a watershed scale. We also hope to introduce the operational effectiveness of this EWS in the weather bureau of Sichuan province.

\section{Wenchuan earthquake-affected region}

The 2008 Wenchuan earthquake-affected area (IIX-XI intensity), with a total area $40162.7 \mathrm{~km}^{2}$, is located in the Longmen Shan Mountains of the northwestern Sichuan Basin (Fig. 1a). The earthquake-affected area within Sichuan Province (Fig. 1b) is selected as the study area. The geological background, topographic setting, and climate characteristics of this region provide advantageous conditions for the development and formation of DFs. Frequent mountain hazards (e.g., DFs and landslides) have brought serious damage to this region throughout history (Xie et al., 2009). Before the 


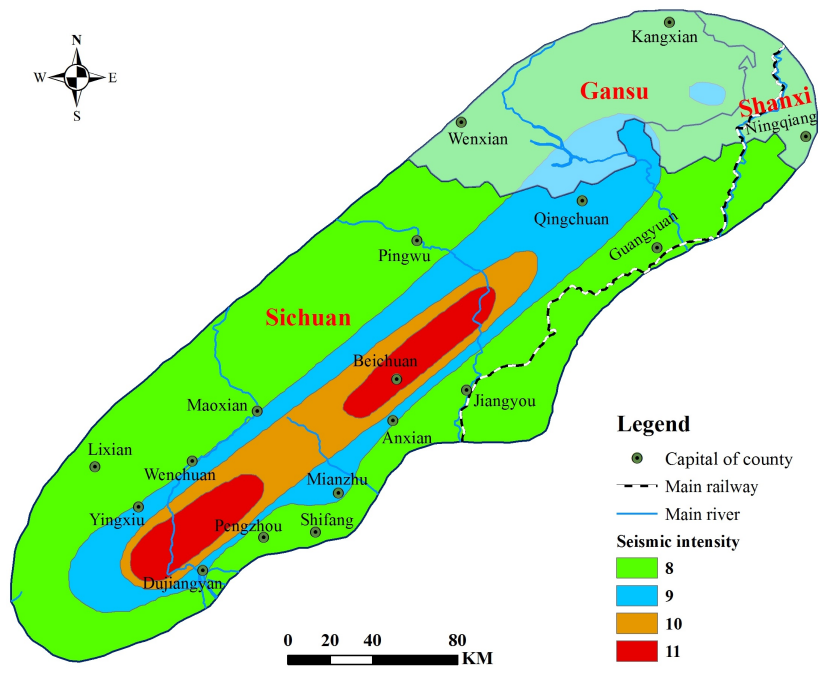

Figure 1. Map of the 2008 Wenchuan earthquake-affected area.

Wenchuan earthquake, there were 320 DF watersheds identified via field observation (Zhong et al., 1997). The number of DF watersheds increased to 669 following the Wenchuan earthquake, according to the data from the Land and Resources Department of Sichuan Province.

\subsection{Topographic setting}

The eastern part of the earthquake-affected area is adjacent to the Sichuan Basin, and the other borders (i.e., the northwest, southwest, and northeast) are adjacent to steep mountains. The terrain variations within this region are large, with elevations ranging from 500 to $5000 \mathrm{~m}$. In general, the western terrain within the region is higher than the eastern. In addition, numerous deep canyons created by large rivers (e.g., the Jialing River, the Fujiang River, and the Minjiang River) are common in this region, and their huge elevation differences and steep slope gradients can provide the energy conditions necessary for DF formation. The elevations and slope gradients of the earthquake-affected region are shown in Fig. 2.

\subsection{Geologic structure}

As the main geological structure of the earthquake-affected region, the Longmen Shan fault zone consists of three fault zones, including the Wenchuan-Maoxian fault, the YingxiuBeichuan fault, and the Peng-Guan fault. Due to its large scale, long geological development, and frequent activity, the Longmen Shan fault zone has provided abundant loose solid material (Xie et al., 2009). The dramatically increased quantity of loose solid material from the Wenchuan earthquakeinduced geological disasters (e.g., collapses, rockfalls, and landslides) further enhanced the development conditions of DFs (Wei et al., 2012).

\subsection{Climate setting}

Due to the blocking action of the Longmen Shan Mountains, the warm and wet air from the southeast makes the piedmont region one of the rainstorm centers of northwestern Sichuan Province, whereas the leeward slopes to the west are dry. Although the mean annual precipitation in the north of Wenchuan, Maoxian, and Lixian counties is $500-800 \mathrm{~mm}$, the maximum daily precipitation can reach $35-75 \mathrm{~mm}$. The mean annual precipitation in the south of Wenchuan, Qingchuan, and Pingwu counties is $800-1200 \mathrm{~mm}$. The mean annual precipitation of the other regions (e.g., Beichuan, Anxian, Shifang, Mianzhu, and Dujiangyan) is greater than $1200 \mathrm{~mm}$ and sometimes even reaches $2500 \mathrm{~mm}$ (Xie et al., 2009). The runoff caused by rainfall is not only the water component of DFs but also provides the power for DF formation.

\section{Debris-flow prediction system based on water-soil coupling mechanism}

\subsection{Prediction mechanism of the system}

The two soil-water coupling processes described above are the main simulation modules in our prediction system. Detailed descriptions are listed in the literature (Zhang et al., 2014a, b). Therefore, we will just provide a brief introduction for the basic principle of this system.

1. Stability variation simulation induced by rainfall $-\mathrm{In}$ fluenced by rainfall infiltration, the increasing soil water content will decrease the matrix suction of the soil mass. This is the main cause of failure in soil masses on slopes. Therefore, based on the failure criterion of the unsaturated soil, the limit equilibrium analysis method with the safety factor $\left(F_{\mathrm{S}}\right)$ is used to estimate the soil mass stability on slopes under the influence of rainfall infiltration (Fig. 3).

$F_{\mathrm{S}}=\frac{\tan \phi}{\tan \beta}+\frac{c+\psi \tan \left(\phi^{b}\right)}{\gamma_{t} H_{\mathrm{s}} \cos \beta \sin \beta}$

where $c(\mathrm{kPa})$ is the soil cohesion force, $\varphi\left(^{\circ}\right)$ is the soil internal friction angle, $\beta\left(^{\circ}\right)$ is the slope gradient, $\gamma_{t}\left(\mathrm{~kg} \mathrm{~m}^{-3}\right)$ is the soil density, $\varphi^{b}\left(^{\circ}\right)$ is related to the matrix suction (which is close to the internal friction angle under conditions of low matrix suction), $H_{\mathrm{S}}(\mathrm{m})$ is the soil depth, and $\psi(\mathrm{kPa})$ is the matrix suction of the soil (which is the function of soil water content).

2. Calculation of the density of the water-soil mixture under the influence of rainfall - DF is a water-soil mixture with a high density, and the density represents the material quantity in the DFs. A certain density of mixture is necessary for the formation of DF at the watershed 

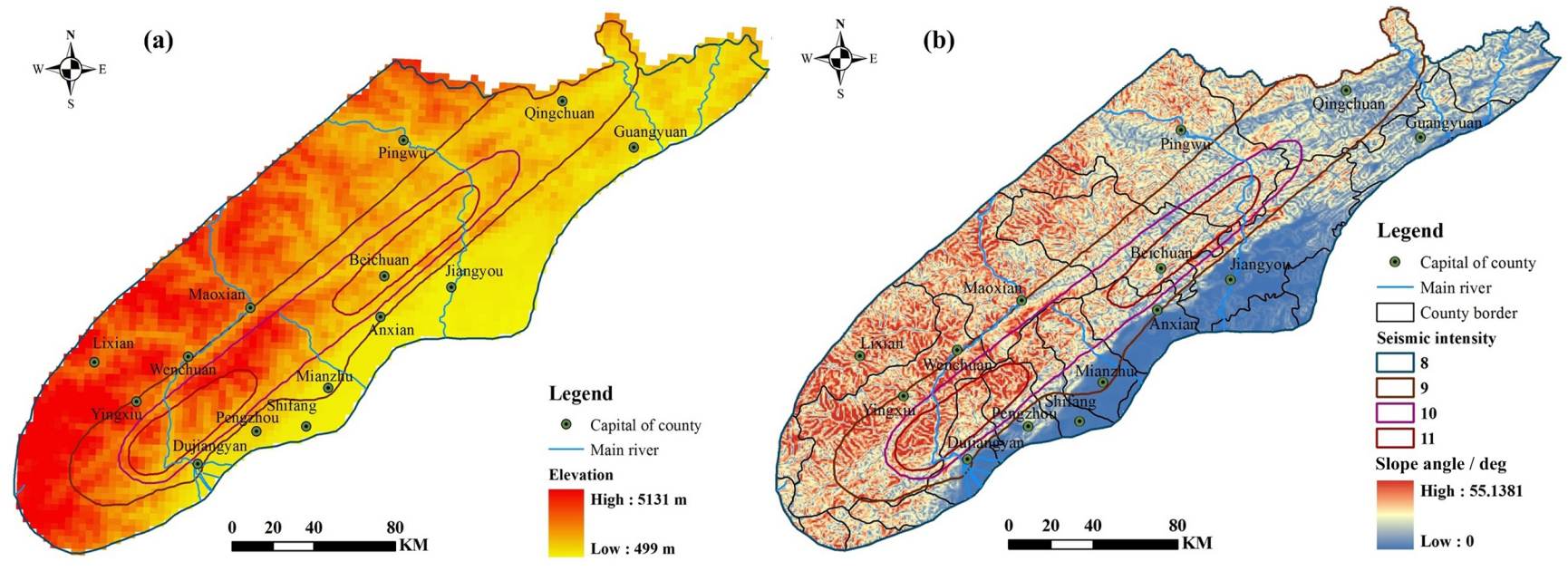

Figure 2. (a) Elevation of the earthquake-affected area; (b) slope angle of the earthquake-affected area.

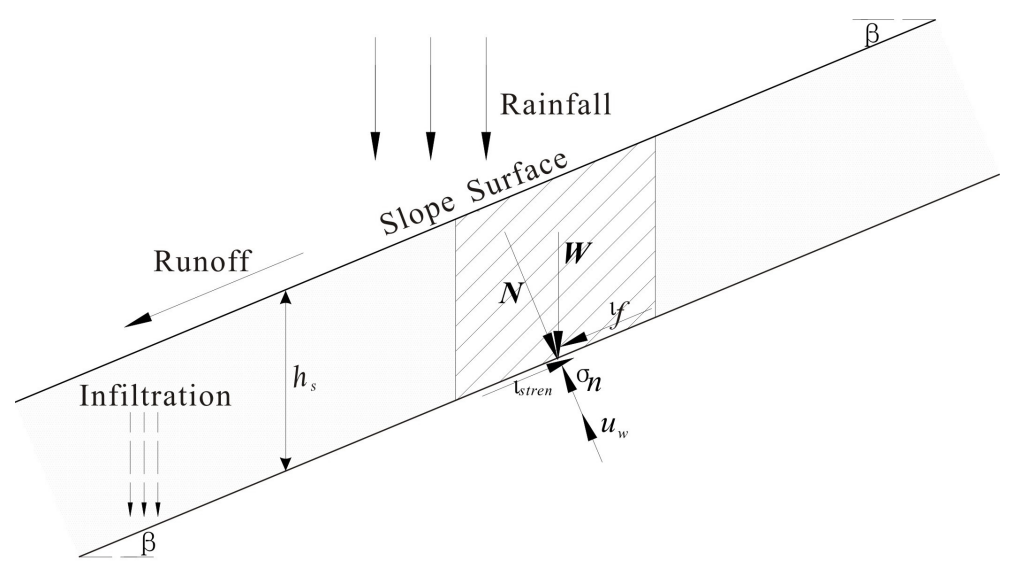

Figure 3. Analysis of soil mass stability influenced by rainfall infiltration.

scale. Therefore, the density of the water-soil mixture, calculated by Eq. (2), can be employed to estimate the DF formation probability at the watershed scale.

$\rho=\frac{\rho_{\mathrm{w}} v_{\mathrm{w}}+\rho_{\mathrm{s}} v_{\mathrm{s}}}{v_{\mathrm{w}}+v_{\mathrm{s}}}$,

where $\rho\left(\mathrm{g} \mathrm{cm}^{-3}\right)$ is the water-soil mixture density, $\rho_{\mathrm{S}}\left(\mathrm{g} \mathrm{cm}^{-3}\right)$ is the soil density (generally, $\left.\rho_{\mathrm{s}}=2.7 \mathrm{~g} \mathrm{~cm}^{-3}\right), \rho_{\mathrm{w}}\left(\mathrm{g} \mathrm{cm}^{-3}\right)$ is the water density, $v_{\mathrm{S}}\left(\mathrm{m}^{3}\right)$ is the unstable soil mass volume, and $v_{\mathrm{w}}\left(\mathrm{m}^{3}\right)$ is the water volume.

3. Estimation of the probability of DF formation based on the mixture density - High density is a key characteristic that distinguishes pure fluid or hyper-concentration debris flow. If there is inadequate soil material from landslides DFs cannot develop even during extreme rainfall, because inadequate landslides cannot guarantee a water-soil mixture reaching to the density standard of DF. The volume of soil mass from landslides is the most important influencing factor on the mixture density. When the volume of unstable soil material from landslides increases, there is a larger density of watersoil mixture, and this creates a more favorable condition for debris flow formation. Therefore, we conclude that when the mixture is denser, the volume of unstable soil material induced by rainfall is greater and debris flow formation is more likely. However, there is no function that can be used to describe this qualitative relationship. According to the research of Kang, the density of the DFs in nature varies in the range of $1.1-2.3 \mathrm{~g} \mathrm{~cm}^{-3}$ (Kang et al., 2004). If natural DF densities are divided into 5 reference intervals, the formation probabilities and warning levels of DFs can be estimated according to these reference intervals (Table 1). Table 1 is specific for our new model and is not suitable for any other DF forecasting model mentioned in this study). 
Table 1. Formation probability of DFs according to the water-soil mixture density.

\begin{tabular}{llllll}
\hline Standard DF density $\left(\mathrm{g} \mathrm{cm}^{-3}\right)$ & $\rho<1.2$ & $\rho=1.2-1.5$ & $\rho=1.5-1.8$ & $\rho=1.8-2.0$ & $\rho=2.0-2.3$ \\
\hline Formation probability of DFs $(\%)$ & $0-20$ & $20-40$ & $40-60$ & $60-80$ & $80-100$ \\
Level of early warning & 1 & 2 & 3 & 4 & 5 \\
Color of early warning & Green & Blue & Yellow & Orange & Red \\
\hline
\end{tabular}

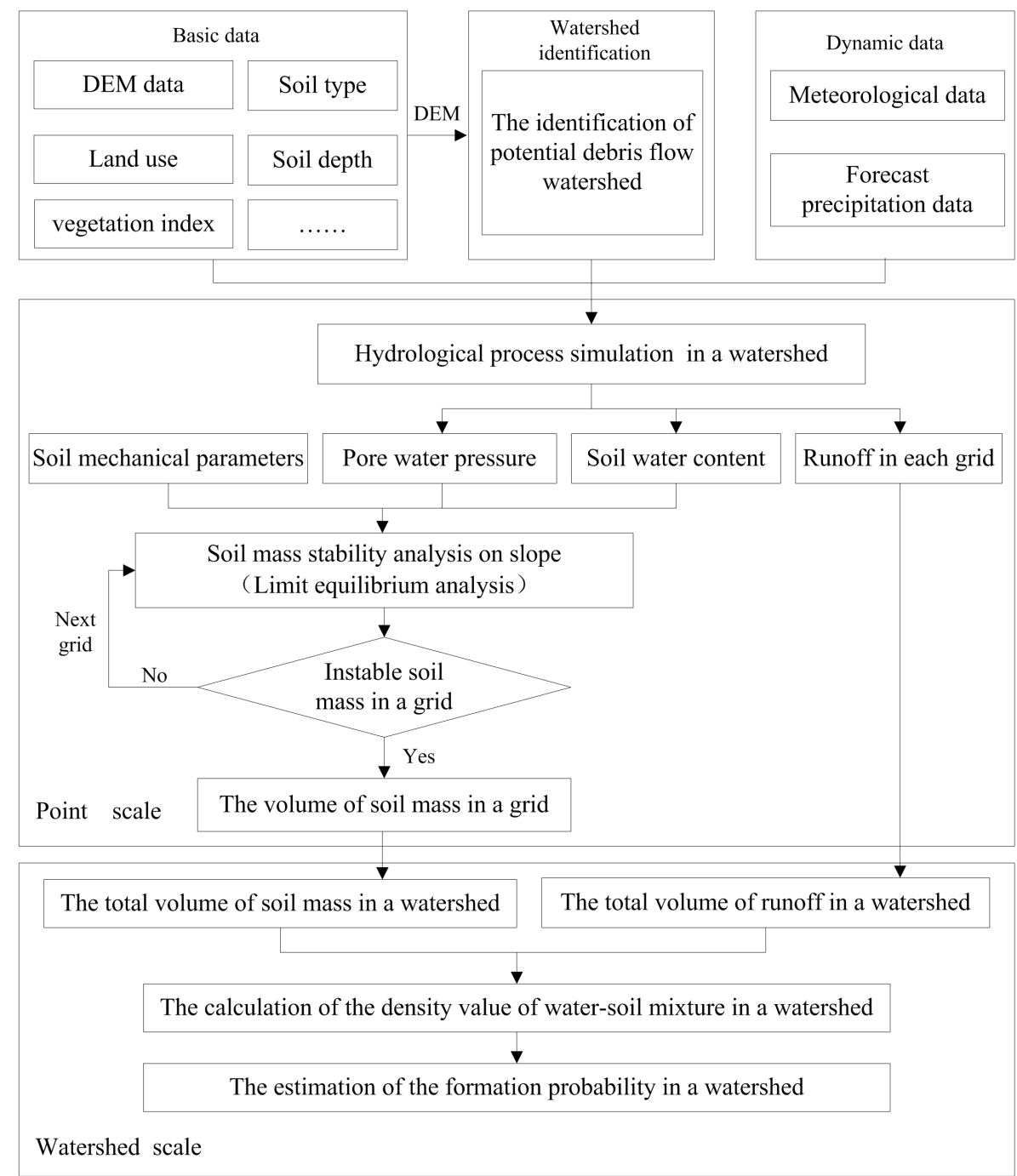

Figure 4. Prediction process of the debris-flow prediction system based on water-soil coupling mechanism.

\subsection{Prediction process of the system}

The workflow of the DF prediction system based on the water-soil coupling mechanism consists of six steps (Fig. 4): basic data preparation, dynamic data inputs, potential DF watershed identification, hydrological process simulation, water-soil mixture density calculation, and estimation of DF formation probability. The core parts of this system are the hydrological process simulation and the calculation of the mixture density, and their objects are potential DF water- sheds. In every prediction process, the soil water content value is first updated and saved from 1 January of the prediction year to the prediction end-point. The value of the soil water content just before the prediction end-point is used as the initial value for the following DF prediction. However, this prediction process takes a long time and cannot satisfy the service requirements of DF prediction. To improve the prediction efficiency, the system should be run once to save the value of the soil water content prior to the rainy season. 
1. Acquiring dynamic data - The dynamic data (meteorological data and predicted precipitation data) are provided by the local bureau of meteorology. The meteorological data (e.g., measured rainfall, temperature, relative humidity, wind velocity, and sunshine duration) for the system should be in a raster format with the same range and resolution as the digital elevation model (DEM). This data can be obtained by using the spatial interpolation method to accommodate the data supplied by weather stations. The predicted precipitation data shares the same format, range, and resolution with the meteorological data. This data can be obtained by using data extraction and resampling techniques to handle the data from Doppler radar.

2. Identification of potential DF watersheds - The system uses the DF watersheds as the prediction units and estimates the formation probability of DFs at the watershed scale. Therefore, it is the principal premise to determine that watersheds in the prediction region have the possibility of DF occurrences. According to previous research, the area of DF watersheds varies from 1 to $100 \mathrm{~km}^{2}$, and more than $80 \%$ of DF watershed areas are less than $10 \mathrm{~km}^{2}$ (Wei et al., 2008). The small watersheds in the prediction region can be extracted via GIS techniques, but not all of them are DF watersheds. At present, there are two methods to identify whether a small watershed has the conditions for DF formation. The first employs field observation to determine whether each small watershed in a prediction region is a DF watershed. The second method is an assessment based on the formation conditions of DFs. Obviously, the first method is superior, but it is too difficult to be applied for large regions. There are three necessary conditions for DF formation: topography, loose solid material, and water. Among these, the latter two conditions change rapidly, whereas the topography can be considered to be invariable over the short term, and it is the basic condition for the formation of DFs. Therefore, according to the topography of the prediction region, the small watersheds that have the basic conditions for DF formation can be extracted and can be taken as the prediction objects in this system.

Xiong (2013) selected the relative height and area of small watersheds as the identification indices to determine the watersheds with the possibility of DF occurrence, and the study established an identification model of potential DF watersheds based on energy conditions.

$\ln (H)-0.2515 \times \ln (A)-3.485>0 A \in\left(0.1,300 \mathrm{~km}^{2}\right)$

, where $H(\mathrm{~m})$ is the relative height of a watershed and $A\left(\mathrm{~km}^{2}\right)$ is the watershed area. If the relative height and area of a small watershed satisfy Eq. (3), the small watershed has the appropriate conditions for DF formation and can be identified as a potential DF watershed.
Based on the energy conditions, an identification subsystem of the potential DF watersheds was established using GIS and database techniques. This subsystem was embedded in our prediction system as an independent module. The identification steps of this subsystem are as follows. (1) Hydrologic modeling is used to extract the small watershed data from the DEM of the prediction region. (2) The raster-to-polygon tool is used to convert the watershed data into vector format data. (3) The calculate-geometry tool is used to compute the area of each watershed. (4) The extract-by-mask tool is used to obtain the DEM of each watershed, as well as the relative height (the difference between the maximum and minimum elevation values), and area of each watershed. (5) The identification model is used to judge whether each watershed is a potential DF watershed.

3. Simulation of hydrological process in watersheds experiencing rainfall - According to Eq. (2), to use the mixture density $\rho$ in the estimation of the formation probability of DFs, the total volume of the unstable soil mass $v_{\mathrm{S}}$ and runoff $v_{\mathrm{w}}$ in each potential DF watershed should be calculated in real time. The two volume values are closely linked with the hydrological parameters of the slopes under the influence of rainfall, i.e., the soil water content, matrix suction, infiltration, and runoff, which can be obtained by the hydrological process simulation of the watersheds. In this research, the distributed hydrological model GBHM (Yang et al., 2002; Cong et al., 2009) is employed to simulate the hydrological processes (e.g., interception, infiltration, and runoff) in the watersheds experiencing rainfall. GBHM has been successfully used to simulate the runoff within the Yangzi River watershed, and its capacity for simulating soil water content has also been verified. The soil water content simulation is the most important component of the DF forecasting model. The Richards (1931) equation is used to describe the water movement in the soil mass and the differential equation is solved via a finite difference method, and the infiltration border is governed by mechanism of runoff generation over infiltration.

For a given watershed, the slope parameters, i.e., the soil cohesive force, internal friction angle, and slope gradient, are provided. According to the limit equilibrium Eq. (1), the safety factor $\left(F_{\mathrm{S}}\right)$ is directly related to the matrix suction of the soil, and the matrix suction is determined by the soil water content. To obtain more accurate hydrological parameters, the initial value of the soil water content in the watersheds should be determined first. However, given the influence of rainfall infiltration and evapotranspiration, the initial value of soil water content at any time cannot be directly calculated. During the winter in China, the soil water content of topsoil is proximate to the residual water content. Therefore, in this study, the initial value of the soil water content is 
calculated by the hydrological process simulation combined with the meteorological data collected from 1 January of the prediction year to the prediction end-point. According to the initial value of the prediction time, the hydrological parameters (e.g., the soil water content and matrix suction) can be assessed by the hydrological process simulation using the radar-predicted precipitation as input.

4. Calculation of the soil-water mixture density in watersheds experiencing rainfall - Taking the soil water content and matrix suction as dynamic inputs, the safety factor $\left(F_{\mathrm{S}}\right)$ of each soil layer in each grid cell can be calculated by using the limit equilibrium Eq. (1). If $F_{\mathrm{s}}<1$, the soil mass of the soil layer in the grid cell is considered to be unstable. According to the unstable depth in grid cells ( $\left.D_{\text {ins }}\right)$ as estimated by $F_{\mathrm{s}}$, the total volume of the unstable soil mass $\left(v_{\mathrm{s}}\right)$ in each watershed at time $t_{0}$ can be calculated in real time via Eq. (4). Based on the mechanism of runoff generation vs. infiltration, the runoff depth $D_{\mathrm{r}}$ of grid cells can be estimated by using the Manning formula (Yen, 1992). According to the $D_{\mathrm{r}}$ of each grid, the total volume of runoff $v_{\mathrm{w}}$ in each watershed at the time $t_{0}$ can be calculated via Eq. (5). Finally, the density value $\rho$ of the soil-water mixture in each watershed can be calculated by the water-soil coupling Eq. (2).

$v_{\mathrm{s}}=\sum_{t=1}^{t=t_{0}} \sum_{i=1}^{N_{\mathrm{ins}}} S_{i} \times D_{\mathrm{ins}}$,

where $v_{\mathrm{s}}\left(\mathrm{m}^{3}\right)$ is the total volume of the unstable soil mass at the time $t_{0}, D_{\text {ins }}(\mathrm{m})$ is the unstable depth of each grid, $S_{i}\left(\mathrm{~m}^{2}\right)$ is the area of each grid, and $N_{\text {ins }}$ is the total quantity of the unstable grids at the time $t_{0}$.

$v_{\mathrm{w}}=\sum_{t=1}^{t=t_{0}} \sum_{i=1}^{N} S_{i} \times D_{\mathrm{r}}$,

where $v_{\mathrm{w}}\left(\mathrm{m}^{3}\right)$ is the total volume of runoff at the time $t_{0}, D_{\mathrm{r}}(\mathrm{m})$ is the runoff depth of each grid, $S_{i}\left(\mathrm{~m}^{2}\right)$ is the area of each grid, and $N$ is the total number of grids in each watershed.

5. Estimation of the probability of DF formation in the watersheds - By comparing the density value $\rho$ of the soilwater mixture within each potential DF watershed with Table 1, the probability interval and the warning level of DF formation within each potential DF watershed can be determined. According to the different warning levels, each potential DF watershed can be marked with a corresponding color, and the early warning information can be published.
Table 2. The land use information in the earthquake-affected area.

\begin{tabular}{llr}
\hline $\begin{array}{l}\text { Number } \\
\text { of land } \\
\text { use type }\end{array}$ & $\begin{array}{l}\text { Name of } \\
\text { land use } \\
\text { type }\end{array}$ & $\begin{array}{r}\text { Percentage } \\
\text { of area/ } \\
\%\end{array}$ \\
\hline 1 & water body & $0.43 \%$ \\
2 & urban area & $0.69 \%$ \\
3 & bare land & $0.16 \%$ \\
4 & forest land & $27.37 \%$ \\
5 & upland & $7.36 \%$ \\
6 & slope cropland & $15.95 \%$ \\
7 & farm land & $26.34 \%$ \\
8 & shrub land & $21.51 \%$ \\
9 & wet land & $0.14 \%$ \\
10 & snow land & $0.05 \%$ \\
\hline
\end{tabular}

\section{DF predictions within the Wenchuan earthquake-affected area}

\subsection{Preparation of basic data}

1. Data for the hydrological process simulation - The hydrological process simulation is performed using grid cells as the basic units. A greater number of grid cells results in lower computational efficiency but higher prediction precision, and vice versa. To improve the prediction efficiency and ensure that the prediction precision meets the demand, a compromise should be found for this problem. Because the commonly used DEM resolutions are 30,90 , and $250 \mathrm{~m}$ and the area of each DF watershed is $0.1-300 \mathrm{~km}^{2}$, the potential DF watershed data are converted to a resolution of $250 \mathrm{~m} \times 250 \mathrm{~m}$ via the resample tool in ArcGIS. By overlaying the potential DF watershed data and the regional DEM $(250 \mathrm{~m} \times 250 \mathrm{~m})$, the elevation information of each potential DF watershed can be obtained.

The original underlying surface data, such as land use type, soil type, and soil depth, in this region can be obtained from the FAO database (http://www.fao.org/ geonetwork/srv/en/main.home). These data sets are also converted into raster data (Fig. 5) with the same resolution as the DEM via the resample tool and the Extract by Mask feature in ArcGIS. The main land use types in this region are forest land, farm land, shrub land, and slope cropland, as shown in Table 2. There are 11 soil types and 2 soil depth types ( 1 and $4 \mathrm{~m}$ ) in this region. The characteristic soil hydraulic parameters of each soil type and the soil depth information are shown in Tables 3 and 4, respectively.

2. Soil mechanical parameters in the earthquake-affected area - The assessment approach for the soil mechanical parameters in the earthquake-affected area consists of three steps. (1) Based on the geological map of 

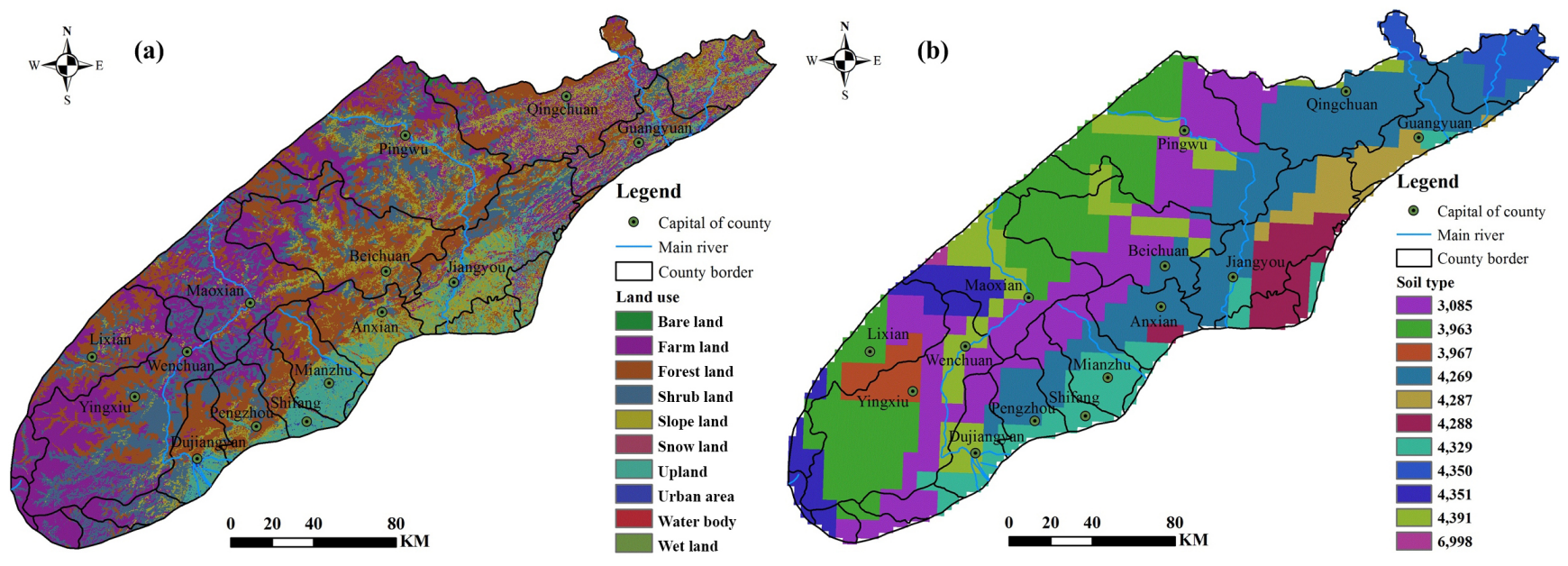

Figure 5. (a) Distribution of land use; (b) distribution of soil type.
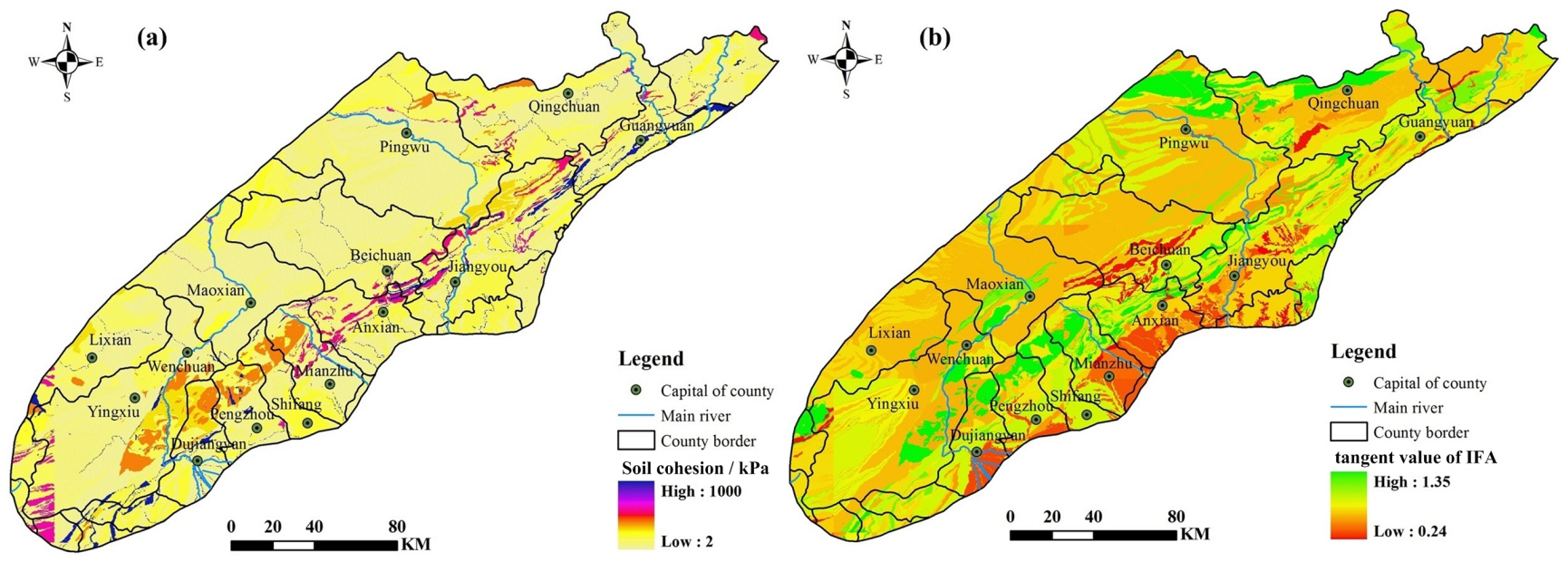

Figure 6. (a) Distribution of the soil cohesion values/kPa; (b) distribution of the tangent value of internal friction angle (IFA).

earthquake-affected area, the lithology of the region is obtained. (2) Based on the handbook of rock mechanics, the mechanical parameters (such as the soil cohesion $c$ and the internal friction angle $\varphi$ ) of the corresponding lithology can be assigned. (3) These mechanical parameter values are then converted into raster data (Fig. 6) with a resolution corresponding to the DEM.

\subsection{Identification of potential DF watersheds}

With the DEM of the earthquake-affected area as the input, the identification subsystem can extract the potential DF watersheds in this region. The identification results show that there are 631 potential DF watersheds in this region. As shown in Fig. 7, we compared the identification result (polygon data) and the 669 identified DF watersheds (point data) based on field observation. In total, $98.7 \%$ of the identified DF watersheds are located in the potential DF watersheds,

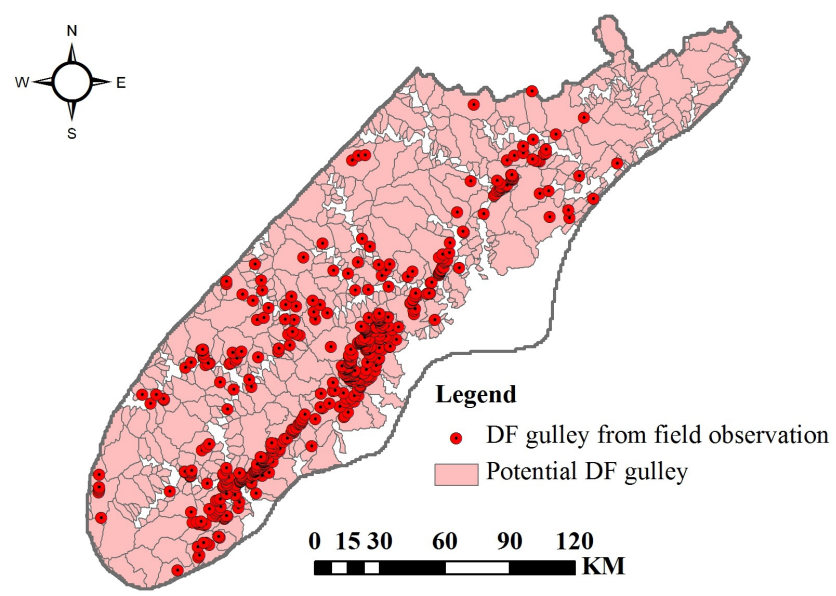

Figure 7. Map of the DF watersheds and potential DF watersheds. 
Table 3. The characteristic soil hydraulic parameters in the earthquake-affected area.

\begin{tabular}{|c|c|c|c|c|c|}
\hline \multirow{2}{*}{$\begin{array}{l}\text { Number of } \\
\text { soil type }\end{array}$} & \multirow{2}{*}{$\begin{array}{l}\text { Saturated } \\
\text { moisture }\end{array}$} & \multirow{2}{*}{$\begin{array}{l}\text { Residual } \\
\text { moisture }\end{array}$} & \multicolumn{2}{|c|}{ Parameters of curve } & \multirow{2}{*}{$\begin{array}{l}\text { Saturated } \\
\text { hydraulic } \\
\text { conductivity } \\
\left(\mathrm{mm} \mathrm{h}^{-1}\right)\end{array}$} \\
\hline & & & $\alpha$ & $n$ & \\
\hline 3085 & 0.48278 & 0.07768 & 0.01896 & 1.40474 & 22.78608 \\
\hline 3963 & 0.47303 & 0.07347 & 0.01796 & 1.42367 & 22.46508 \\
\hline 4269 & 0.45649 & 0.06905 & 0.02306 & 1.55872 & 32.68625 \\
\hline 4270 & 0.45252 & 0.07062 & 0.02221 & 1.53008 & 27.76813 \\
\hline 4287 & 0.44596 & 0.07343 & 0.01971 & 1.47235 & 19.30871 \\
\hline 4288 & 0.43797 & 0.07175 & 0.02064 & 1.53067 & 24.80996 \\
\hline 4329 & 0.45049 & 0.07957 & 0.01604 & 1.44517 & 9.307170 \\
\hline 4350 & 0.47990 & 0.07435 & 0.02156 & 1.42176 & 22.51646 \\
\hline 4351 & 0.48278 & 0.07723 & 0.02040 & 1.41974 & 21.61279 \\
\hline 4391 & 0.42784 & 0.06439 & 0.01623 & 1.63524 & 23.91267 \\
\hline 6998 & 0.46154 & 0.06817 & 0.01770 & 1.46884 & 23.60925 \\
\hline
\end{tabular}

Table 4. The soil depth information in earthquake-affected area.

\begin{tabular}{lclllllll}
\hline \multirow{2}{*}{$\begin{array}{l}\text { Depth/ } \\
\mathrm{m}\end{array}$} & $\begin{array}{r}\text { Percentage } \\
\text { of area/\% }\end{array}$ & 1 & 2 & 3 & 4 & 5 & 6 & 7 \\
\cline { 3 - 9 } & $43.5 \%$ & 0.025 & 0.05 & 0.75 & 0.1 & 0.15 & 0.25 & 0.35 \\
4 & $56.5 \%$ & 0.1 & 0.2 & 0.3 & 0.4 & 0.6 & 1.0 & 1.4 \\
\hline
\end{tabular}

and certain identified DF watersheds may be located in the same potential DF watershed. Some missing points are near the edge of the potential DF watersheds, and the other missing points are almost all located in the Sichuan Basin.

\subsection{Input of dynamic data}

1. Input of meteorological data - The original meteorological data, including the 65 weather stations in the earthquake-affected area and nearby regions (Fig. 8), are provided by the weather bureau of Sichuan province. The meteorological data from each weather station consist of measured rainfall, temperature (maximum, mean, and minimum temperature), wind velocity, relative humidity, and duration of sunshine. According to the coordinate information of each weather station, these data are converted into raster data with a resolution corresponding to the DEM via the Kriging spatial interpolation method.

2. Input of radar-predicted precipitation data - The original predicted precipitation data in the earthquakeaffected area on 17 August 2012 are provided by the weather bureau of Sichuan province, but they do not directly meet the demands of this prediction system. The predicted precipitation data for this prediction system should have the same resolution and coverage area as the DEM of this region. Therefore, according to the

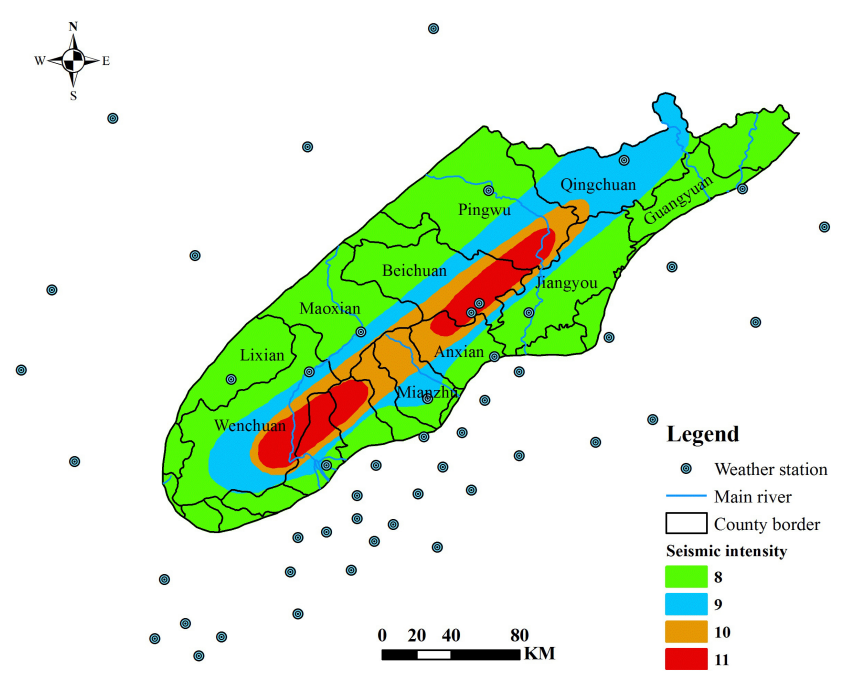

Figure 8. Distribution of weather stations in the earthquake-affected area and nearby regions.

original predicted precipitation data and this regional DEM, the predicted precipitation data for this prediction system can be generated using resampling techniques, etc. (Fig. 9). 


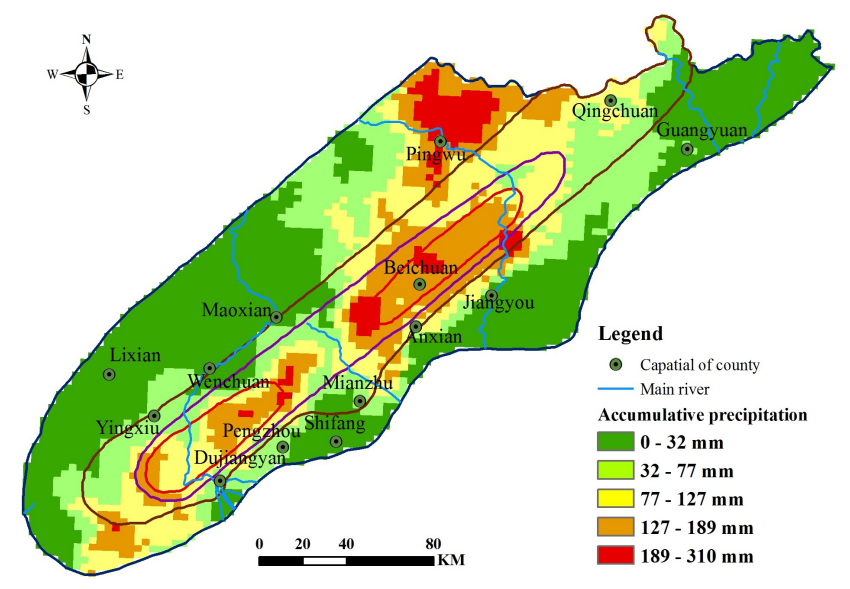

Figure 9. Predicted distribution of $24 \mathrm{~h}$ of cumulative precipitation.

\subsection{Results and analysis of the prediction}

The formation probability and the warning level of each potential DF watershed in the earthquake-affected area were predicted for 17 August 2012 via the DF prediction system based on the water-soil coupling mechanism. The prediction results at Beijing time zone 19:00 p.m. are shown in Fig. 10. According to the DF events reported by the Land and Resources Department of Sichuan Province, 156 watersheds experienced DFs in the Wenchuan earthquake-affected area. The results of this prediction system show that there are 161 watersheds that are at risk for DFs. The false negative rate (in which DFs occurred but were not predicted) is $19 \%$, and the false positive rate (in which DFs are predicted, but no DFs occurred) is $21 \%$. Further analysis of the watersheds with false negative shows that there are 4 watersheds (labeled as "Unsuccessful watersheds: 1" in Fig. 10) that are not classified as potential DF watersheds, and that the 24 hours of cumulative precipitation is less than $20 \mathrm{~mm}$ in 6 watersheds (labeled as "Unsuccessful watersheds: 2" in Fig. 10). If these 10 watersheds with false negatives are excluded for the two reasons mentioned above, there are 19 watersheds with false negatives (labeled as "Unsuccessful watersheds: 3" in Fig. 10). We therefore conclude that the actual false negative rate for the system is only $12 \%$. As for the 34 watersheds with false positives, a portion of them were actually caused by the precision of the radar prediction rainfall. The radar prediction precipitation in the 16 watersheds with false positives nearly exceeded $100 \mathrm{~mm}$ on the prediction day. As a consequence, the warning level generated by the system ranged from green to orange with the radar prediction rainfall as input. However, the observed rainfall (Fig. 11) in these 16 watersheds was less than $10 \mathrm{~mm}$ (labeled as "Watersheds: false-positive" in Fig. 11). This was far smaller than the radar prediction precipitation and represents a condition in which DFs are difficult to trigger. Thus, if the 16 water-

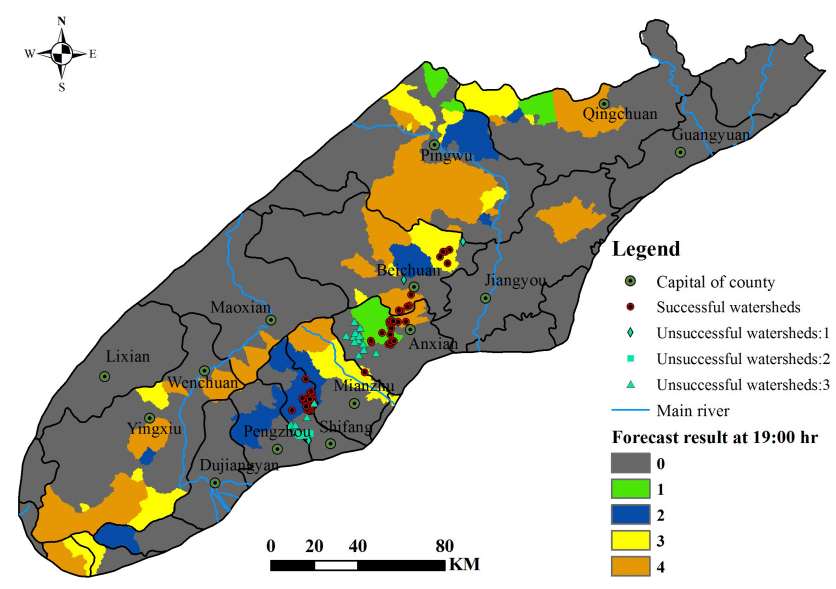

Figure 10. Prediction results of the debris-flow prediction system based on the water-soil coupling mechanism.

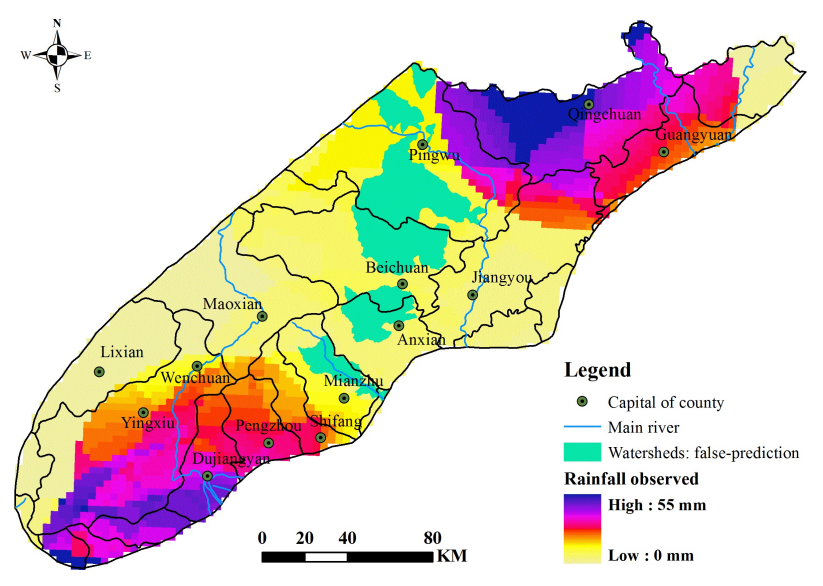

Figure 11. Distribution of observed rainfall for the prediction day in the earthquake-affected area.

sheds with false positives are excluded for this reason, the false positive rate for the system is only $11 \%$.

The formation probability of DFs in this region on the prediction day is also forecasted by the system based on the DF contribution factors from the weather bureau of Sichuan Province. The so called DF contribution factors mean the variables that can contribute to DF formation, which include rainfall, fault activity, lithology, and slope, etc. (Wei et al., 2006, 2007). This system divides the critical rainfall into a series of grade intervals according to the different conditions of DF formation, and it then utilizes fuzzy mathematics to determine the formation probability of DFs based on the predicted precipitation interval range and the underlying surface conditions (Wei et al., 2006, 2007). The prediction results for 17 August 2012 are shown in Fig. 12.

According to the Fig. 12, the expression mode of the warning level in the prediction system based on the DF contribution factors is entirely grid-unit based. But DF generally occurred in a relatively small watershed (Wei et al., 2008), 
Table 5. Comparison of the prediction results of the two systems.

\begin{tabular}{lll}
\hline Prediction system & $\begin{array}{l}\text { Water-soil } \\
\text { coupling } \\
\text { mechanism }\end{array}$ & $\begin{array}{l}\text { Contribution } \\
\text { factors }\end{array}$ \\
\hline Number of watersheds with predicted DFs & 161 & 192 \\
Number of watersheds with actual DFs & 156 & 156 \\
Number of watersheds with both predicted and actual DFs & 127 & 106 \\
Number of watersheds with DF prediction failures & 29 & 50 \\
Number of false prediction watersheds & 34 & 86 \\
False negative rate & $19 \%$ & $32 \%$ \\
False positive rate & $21 \%$ & $45 \%$ \\
\hline
\end{tabular}

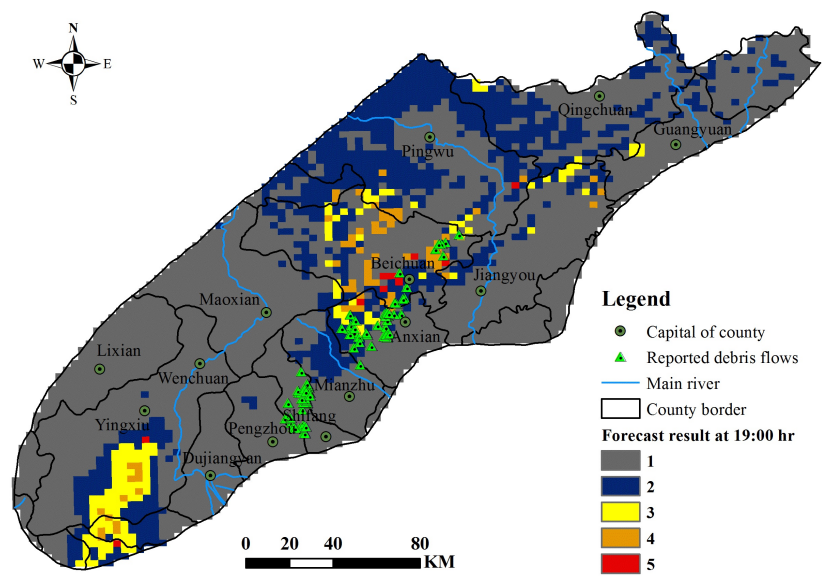

Figure 12. Prediction results of the debris-flow prediction system based on contribution factors.

and the grid unit is difficult to express the morphology of a DF watershed. So the expression format using the grid unit should be replaced by the watershed unit. There are two rules that govern the above-mentioned transformation process: the rule of highest warning level (the warning level of a watershed is assigned the highest warning level within the watershed) and the rule of most quantity warning level (the warning level of a watershed corresponds to the predominant warning level within the watershed). Figures 13 and 14 indicate that some watersheds can even adopt two different warning levels according to the above-mentioned two rules; therefore the transformation results are somewhat uncertain. Additionally, this transformation process requires a significant amount of manual labor, and it is therefore not beneficial to the real-world DF prediction.

The results obtained by the above-mentioned two prediction systems are compared to test the capacity of our proposed system. The comparison results listed in Table 5 indicate that the prediction results of our system are quite good, with false negative and false positive rates of 19 and $21 \%$, respectively. These rates were lower than those based on the DF contribution factors (32 and $45 \%$, respectively). However, it

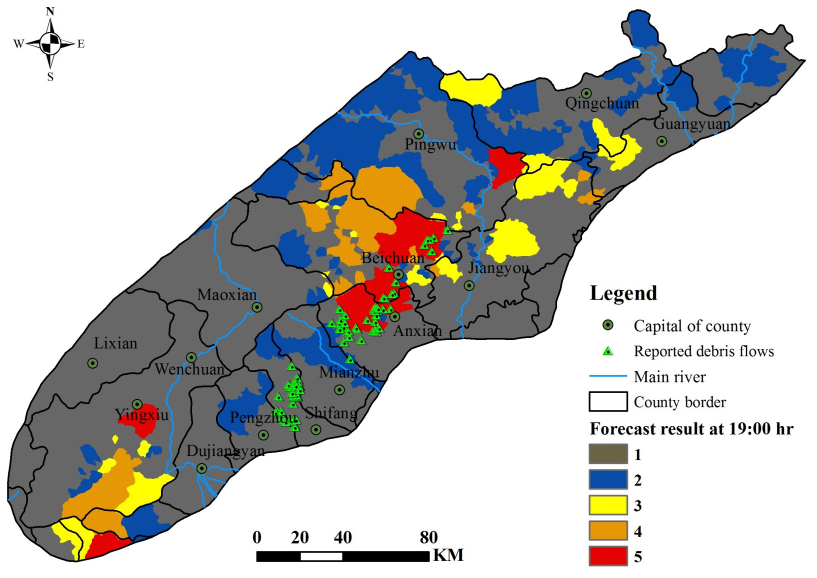

Figure 13. Transformation of results via the rule of highest warning level.

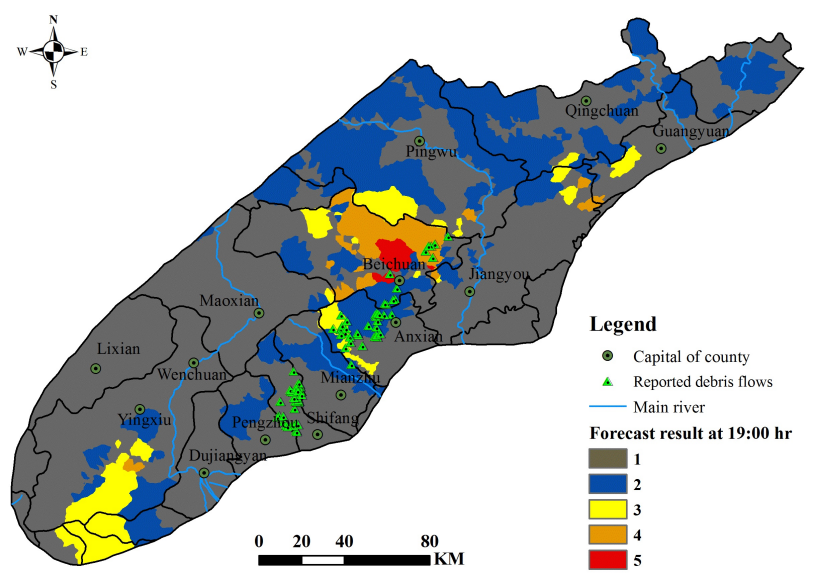

Figure 14. Transformation of results via the rule of most common warning level.

should be noted that the calculation of initial soil water content for DF forecasting is time consuming. This situation is not beneficial to the operation and represents a disadvantage 

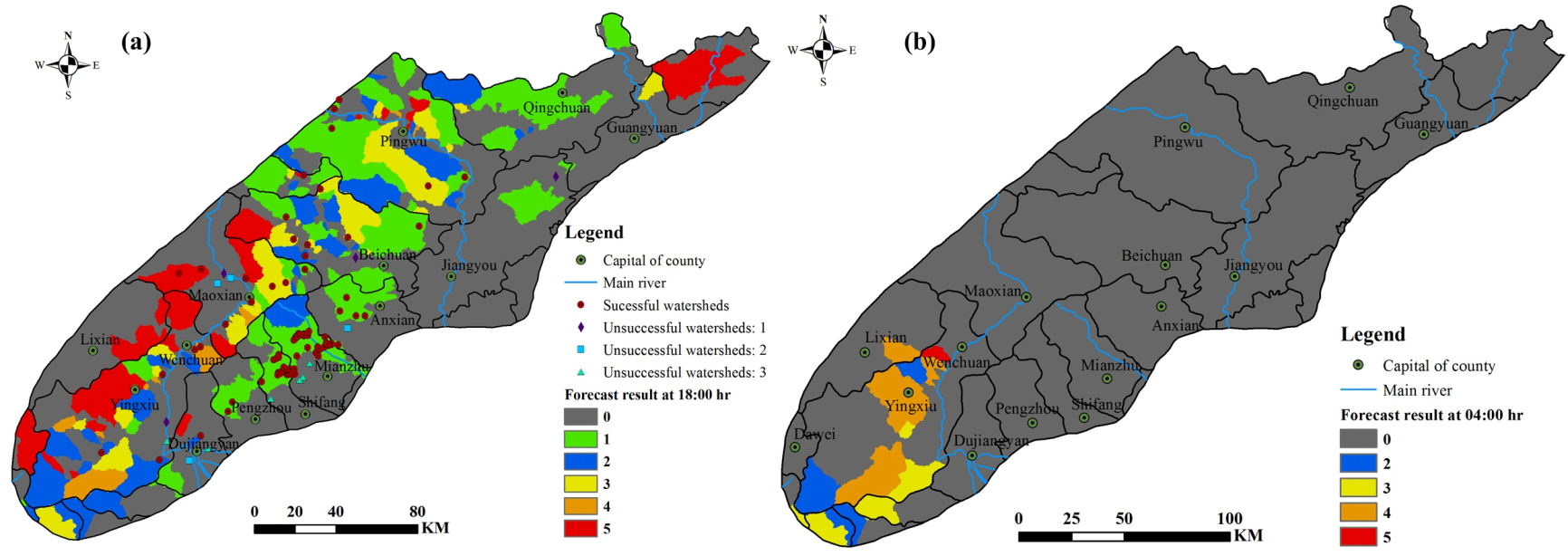

Figure 15. (a) Prediction results of the debris-flow prediction system based on the water-soil coupling mechanism at 18:00 p.m. Beijing time zone on 9 July 2013; (b) prediction results of the debris-flow prediction system based on the water-soil coupling mechanism at 04:00 a.m. Beijing time zone on 10 July 2014.

relative to the current early warning system based in contributing factors.

\section{Applications of new prediction system at the Sichuan weather bureau}

Due to advantages of the new prediction system compared to the system currently used in operational forecasting projects, the new system was installed at the Sichuan weather bureau in the Wenchuan earth quake-affected area before the rainy season in 2013. The prediction results for 9 July 2013 and 10 July 2014 as generated by the new prediction system are respectively shown in Fig. 15. The false negative and false positive rates of the prediction result for 9 July 2013 are 16 and $22 \%$, respectively (Table 6).

The DF events in 2014 were not very remarkable, and the exact information of DF events (e.g., the time and place) is not available for this research. However, there is still some helpful information on DF events that can be collected from the Internet. For example, on 10 July 2014, it was reported that there were DF events in six townships in Lixian County, one town in Xiaojin County, and three towns in Wenchuan County. The radar rainfall on 10 July 2014 was used in the new prediction system. The DF prediction results shown in Fig. 15b show a good agreement with the reported information from the Internet (http://www.qimaren.com/news/2014/ 07/10_3104.html). The operational forecasting conducted in 2013 and 2014 demonstrated that the new prediction system installed at the weather bureau of Sichuan province had an excellent operational stability with a high prediction capacity and precision.
Table 6. Analysis of forecasting results on 9 July 2013.

\begin{tabular}{ll}
\hline Number of watersheds with predicted DFs & 169 \\
\hline Number of watersheds with actual DFs & 157 \\
Number of watersheds with both predicted and actual DFs & 132 \\
Number of watersheds with DF prediction failures & 25 \\
Number of false prediction watersheds & 37 \\
False negative rate & $16 \%$ \\
False positive rate & $22 \%$ \\
\hline
\end{tabular}

\section{Discussion and conclusions}

A novel physics-based EWS for DF forecasting was developed and installed in the weather bureau of Sichuan province. The three typical cases studies demonstrated that this EWS has a high operational stability and high prediction accuracy. However, there are several problems with this EWS that need to be studied further. First, the hydrological simulation in this system is so complicated that it will result in a timeconsuming prediction process. The calculation of the initial soil water content value for DF prediction is especially time intensive which creates difficulty in meeting the demand of an operational prediction as this calculation process is from 1 January to the prediction end-point with a calculation step of $1 \mathrm{~h}$. To improve the prediction efficiency, antecedent rainfall could be solved by continuously running the model, in this way, the antecedent conditions are ready every day for the computation of possible DF triggering. Another issue is that the total volume of unstable soil mass is used in this system to calculate the density of the water-soil mixture within a watershed. It is assumed that once a soil mass fails, its entire extent will participate in the water-soil coupling process. However, portions of the unstable soil mass may remain on slopes instead of moving into the channel. This will result 
in over-estimation of density values calculated by this system. Additionally, another issue that can influence the soil mass volume participation in the water-soil coupling process is the soil porosity. This variable can also influence the water volume due to pore water. To obtain more accurate density values, the movement process of unstable soil masses and the role of soil porosity require further study. An additional problem with the system is that the density of the water-soil mixture is used to quantitatively characterize the complex dynamic formation process of DFs. Therefore, this method cannot completely describe this complex dynamic process and represents a grey-box model. To reflect the formation of DFs at the watershed scale more completely, the dynamic DF formation process in watersheds needs to be studied further. Lastly, there are two supplement patterns of material source for DF formation, rainfall-induced landslides from slopes in watersheds and deposits in channel beds eroded by the runoff. The underlying theory of this prediction system is based on the coupling of runoff and solid material from rainfall-induced landslides. Obviously, this prediction system will not work well for predicting DFs with the other sources of material.

Acknowledgements. This research was supported by the Science and Technology Service Network Initiative (No. KFJ-SW-STS180), the foundation of the Research Fund for Commonweal Trades (Meteorology) (No. GYHY201006039), the Science and Technology Support Project of Sichuan Province (No. 2015SZ0214), the National Natural Science Foundation of China (No. 61501064, No. 41501114). We appreciate the weather bureau of Sichuan Province for the data services.

Edited by: H. Mitasova

Reviewed by: two anonymous referees

\section{References}

Aletti, P.: A warning system for rainfall-induced shallow failures, Eng. Geol., 73, 247-265, 2004.

Badoux, A., Turowski, J. M., Mao, L., Mathys, N., and Rickenmann, D.: Rainfall intensity-duration thresholds for bedload transport initiation in small Alpine watersheds, Nat. Hazards Earth Syst. Sci., 12, 3091-3108, doi:10.5194/nhess-12-30912012, 2012.

Berenguer, M., Sempere-Torres, D., and Hürlimann, M.: Debrisflow forecasting at regional scale by combining susceptibility mapping and radar rainfall, Nat. Hazards Earth Syst. Sci., 15, 587-602, doi:10.5194/nhess-15-587-2015, 2015.

Berti, M. and Simoni, A.: Experimental evidences and numerical modeling of debris flow initiated by channel runoff, Landslides, 2, 171-182, 2005.

Borga, M., Stoffel, M., Marchi, L., Marra, F., and Jakob, M.: Hydrogeomorphic response to extreme rainfall in headwater systems: Flash floods and debris flows, J. Hydrol., 518, 194-205, 2014.

Caine, N.: The rainfall intensity-duration control of shallow landslides and debris flows, Geografiska Ann. A, 62, 23-27, 1980.
Chen, H. and Lee, C. F.: Geohazards of slope mass movement and its prevention in Hong Kong, Eng. Geol., 76, 3-25, 2004.

Coe, J. A., Kinner, D. A., and Godt, J. W.: Initiation conditions for debris flows generated by runoff at Chalk Cliffs, central Colorado, Geomorphology, 96, 270-297, 2008.

Cong, Z. T., Yang, D. W., Gao, B., Yang, H. B., and Hu, H. P.: Hydrological trend analysis in the Yellow River basin using a distributed hydrological model, Water Resour. Res., 45, W00A13, doi:10.1029/2008WR006852, 2009.

Cui, P.: Experiment Research of the Initial Condition and Mechanism of debris flow, Chinese Sci. Bull., 21, 1650-1652, 1991

Cui, P., Zhou, G. D., Zhu, X. H., and Zhang, J. Q.: Scale amplification of natural ebris flows caused by cascading landslide dam failures, Geomorphology, 182, 173-189, 2013.

European Commission D. G. Environment: Member States' approaches towards prevention policy - a critical analysis, Final Report, Denmark, 2008.

Gariano, S. L., Brunetti, M. T., Iovine, G., Melillo, M., Peruccacci, S., Terranova, O., Vennari, C., and Guzzetti, F.: Calibration and validation of rainfall thresholds for shallow landslides forecasting in Sicily, Southern Italy, Geomorphology, 228, 653-665, doi:10.1016/j.geomorgh.2014.10.019, 2015.

Giannecchini, R., Galanti, Y., and D’Amato Avanzi, G.: Critical rainfall thresholds for triggering shallow landslides in the Serchio River Valley (Tuscany, Italy), Nat. Hazards Earth Syst. Sci., 12, 829-842, doi:10.5194/nhess-12-829-2012, 2012.

Guzzetti, F., Peruccacci, S., Rossi, M., and Stark, C. P.: Rainfall thresholds for the initiation of landslides in central and southern Europe, Meteorol. Atmos. Phys., 98, 239-267, 2007.

Guzzetti, F., Peruccacci, S., Rossi, M., and Stark, C. P.: The rainfall intensity-duration control of shallow landslides and debris flow: an update, Landslides, 5, 3-17, 2008.

Iverson, R. M., Reid, M. E., and LaHusen, R. G.: Debris-flow mobilization from landslides, Ann. Rev. Earth Planet. Sci., 25, 85138, 1997.

Kang, Z. C.: The mechanical analysis of the generation of debris flow, Mountain Res., 5, 225-230, 1987.

Kang, Z. C., Li, C. F., and Ma, A. N.: Debris flow Research in China, Science Press, Beijing, 21-22, 2004.

Kean, J. W., McCoy, S. W., Tucker, G. E., Staley, D. M., and Coe, J. A.: Runoff-generated debris flows: observation and modeling of surge initiation, magnitude, and frequency, J. Geophys. Res.Earth, 118, 2190-2207, 2013.

Kim, S. and Lee, H.: A study of the debris flow activity on the onestepped channel slope, Soil Water Res., 10, 32-39, 2015.

Li, Y. F., Wang, Z. Y., Shi, W. J., and Wang, X. Z.: Slope Debris Flows in the Wenchuan Earthquake Area, J. Mount. Sci., 7, 226233, 2010.

Ni, H. Y.: Experimental study on initiation of gully-type debris flow based on artificial rainfall and channel runoff, Environ. Earth Sci., 73, 6213-6227, 2015.

Osanai, N., Shimuzu, T., Kuramoto, K., and Noro, T.: Japanese early-warning for debris flows and slopes failures using rainfall indices with radial basis function network, Landslides, 7, 325338, 2010.

Papa, M. N., Medina, V., Ciervo, F., and Bateman, A.: Derivation of critical rainfall thresholds for shallow landslides as a tool for debris flow early warning systems, Hydrol. Earth Syst. Sci., 17, 4095-4107, doi:10.5194/hess-17-4095-2013, 2013. 
Richards, L. A.: Capillary conduction of liquids in porous mediums, Physics, 1, 318-333, 1931.

Tang, C., Zhu, J., Li, W. L., and Liang, J. T.: Rainfall-triggered debris flows following the Wenchuan earthquake, Bull. Eng. Geol. Environ., 68, 187-194, 2009.

Vennari, C., Gariano, S. L., Antronico, L., Brunetti, M. T., Iovine, G., Peruccacci, S., Terranova, O., and Guzzetti, F.: Rainfall thresholds for shallow landslide occurrence in Calabria, southern Italy, Nat. Hazards Earth Syst. Sci., 14, 317-330, doi:10.5194/nhess-14-317-2014, 2014.

Wei, F. Q., Tang, J. F., Xie, H., and Zhong, D. L.: Debris Flow Forecast Combined Regions and Valleys and Its Application, J. Mount. Sci., 22, 321-325, 2004.

Wei, F. Q., Gao, K. C., Cui, P., Hu, K., Xu, J., Zhang, G., and Bi, B.: Method of debris flow prediction based on a numerical weather forecast and its application, in: Monitoring, simulation, prevention and remediation of dense and debris flow, edited by: Lorenzini, G., Brebbia, C. A., and Emmanouloudis, D. E., WIT Press, Southampton, 37-46, 2006.

Wei, F. Q., Gao, K. C., Jiang, Y. H., Jia, S. W., Cui, P., Xu, J., Zhang, G. P., and Bi, B. G.: GIS-Based Prediction of Debris Flows and Landslides in Southwestern China, in: Proceedings of Debris-Flow Hazards Mitigation: Mechanics, Prediction, and Assessment, edited by: Chen, C. L. and Major, J. J., Mill Press, the Netherlands, 479-490, 2007.

Wei, F. Q., Gao, K. C., Hu, K. H., Li, Y., and Gardner, J. S.: Relationship between debris flows and earth surface factors in Southwest China, Environ. Geol., 55, 619-627, 2008.

Wei, F. Q., Su, P. C., and Jiang, Y. H.: Distribution characteristics of landslides and debris flows in the wenchuan earthquake region before and after the Earthquake, Disaster Adv., 5, 285-294, 2012.
Xie, H., Zhong, D. L., Jiao, Z., and Zhang, J. S.: debris flow in Wenchuan quake-hit area in 2008, J. Mount. Sci., 27, 501-509, 2009.

Xiong, J. N.: Refined regional debris flow risk assessment based on remote sensing and GIS, Thesis for Degree of Doctor of University of Chinese Academy of Science, Beijing, 2013.

Yang, D. W., Herath, S., and Musiake, K.: A hillslope-based hydrological model using catchment area and width function, Hydrolog. Sci. J., 47, 231-243, 2002.

Yen, B. C.: Dimensionally homogeneous Manning's formula, J. Hydraul. Eng., 118, 1326-1332, 1992.

Zeng, F. Q., Xu, G., and Li, Q.: Critical gradient and debris flow on mountain slope, Scient. Geogr. Sin., 25, 245-247, 2005.

Zhang, S. J., Yang, H. J., Wei, F. Q., Jiang, Y. H., and Liu, D. L.: A model of debris flow forecast based on the water-Soil coupling mechanism, J. Earth Sci., 25, 757-763, 2014a.

Zhang, S. J., Wei, F. Q., Liu, D. L., Yang, H. J., and Jiang, Y. H.: A regional-scale method of forecasting debris flow events based on water-soil coupling mechanism, J. Mount. Sci., 11, 1531-1542, 2014b.

Zhang, S. J., Wei, F. Q., Liu, D. L., and Jiang, Y. H.: Analysis of slope stability based on the limit equilibrium equation and the hydrological simulation, J. Basic Sci. Eng., in press, 2016.

Zhong, D. L., Xie, H., and Wei, F. Q.: Map of debris flow Distribution and Danger Degree Division in Sichuan and Chongqing and Its Manual, Chengdu Cartographic Publishing House, Chengdu, 1997. 